\title{
Corrosion resistance of steels with ultrafine grained structure in hydrogen sulfide environment
}

\author{
G. V. Klevtsov ${ }^{\dagger, 1}$, R.Z. Valiev², N. A. Klevtsova ${ }^{1}$, E. D. Merson ${ }^{1}$, I. N. Pigaleva ${ }^{1}$ \\ ${ }^{\dagger}$ Klevtsov11948@mail.ru \\ ${ }^{1}$ Togliatti State University, 14 Belorusskaya St., Togliatti, 445020, Russia \\ ${ }^{2}$ Institute of Physics of Advanced Materials, Ufa State Aviation Technical University, 12 K. Marx St., Ufa, 450008, Russia

\begin{abstract}
The regularities of the influence of hardness, strength and ductility of steels with ultrafine-grained (UFG) structure on the rate and peculiarities of corrosion in the hydrogen sulfide-containing medium in comparison with steels with the coarsegrained (CG) structure were investigated. Low-alloyed pipe steel 9MnSi5 and carbon steels: C10 and C45 were used as the materials under study. The UFG condition of the steels was obtained by equal channel angular pressing (ECAP) and by ECAP-conform. It is shown that with an increase in the amount of carbon in the CG steels subjected to normalization, and the UFG steels after ECAP, the corrosion rate in the hydrogen sulfide medium increases. With the same hardness value of steels with CG and UFG structures, the latter can have a lower or higher corrosion rate compared with CG steels, depending on the amount of carbon and heat treatment of CG steels. Moreover, the same increment of the corrosion rate in steels with a CG structure is achieved with smaller values of the hardness increment compared with steels having a UFG structure obtained by ECAP. With the same value of strength or ductility of CG and UFG steels, steels with UFG structure have the same or greater corrosion resistance as compared to steels with a CG structure. After the effect of the corrosion environment on the CG steels in the initial state (after normalization), general and intergranular corrosion dominate. With increasing carbon content in steel, peptic ulcer corrosion appears. In UFG steels (obtained by ECAP), in addition to general corrosion, there is spot corrosion and peptic corrosion.
\end{abstract}

Keywords: UFG and CG steel, equal-channel angular pressing (ECAP), mechanical properties, corrosion rate.

УДК: 621.793(07)

\section{Коррозионная стойкость сталей с ультрамелкозернистой структурой в сероводородсодержащей среде}

\author{
Клевцов Г. В. ${ }^{\dagger,}$, Валиев Р. 3. ${ }^{2}$, Клевцова Н. А. ${ }^{1}$, Мерсон Е. Д. ${ }^{1}$, Пигалева И. Н. ${ }^{1}$ \\ ${ }^{1}$ Тольяттинский государственный университет, ул. Белорусская, 14, Тольятти, 445020, Россия \\ ${ }^{2}$ НИИ Физики перспективных материалов, Уфимский государственный авиационный технический университет, \\ ул. К. Маркса, 12, Уфа, 455000, Россия
}

\begin{abstract}
Исследовали закономерности влияния твердости, прочности и пластичности сталей с ультрамелкозернистой (УМЗ) структурой на скорость и особенности коррозии в сероводородсодержащей среде в сравнении со сталями с крупнозернистой (КЗ) структурой. В качестве исследуемых материалов были использованы низколегированная трубная сталь 9MnSi5 и углеродистые стали: С10 и С45. УМЗ состояние сталей было получено путем равноканального углового прессования (РКУП) и путем РКУП-конформ. Показано, что с увеличением количества углерода в КЗ сталях, подвергнутых нормализации, и УМЗ сталях после РКУП скорость коррозии в сероводородсодержащей среде возрастает. При одинаковом значении твердости сталей с КЗ и УМЗ структурой, последние могут иметь меньшую или большую скорость коррозии по сравнению с КЗ сталями в зависимости от количества углерода и термической обработки КЗ сталей. Причем, одно и то же приращение скорости коррозии в сталях с КЗ структурой достигается при меньших значениях приращения твердости по сравнению со сталями, имеющими УМЗ структуру, полученную путем РКУП. При одинаковом значении прочности или пластичности сталей с КЗ и УМЗ структурой, стали с УМЗ структурой обладают такой же или большей коррозионной стойкостью по сравнению со сталями с КЗ структурой. При воздействии коррозионной среды на КЗ стали в исходном состоянии (после нормализации) доминируют общая и межзеренная коррозия. С увеличением в сталях количества углерода появляется язвенная коррозия. В УМЗ сталях (полученных путем РКУП), помимо общей коррозии, имеют место коррозия пятнами и язвенная коррозия.
\end{abstract}

Ключевые слова: УМЗ и КЗ стали, равноканальное угловое прессование (РКУП), механические свойства, скорость коррозии. 


\section{1. Введение}

Объемные наноструктурированные металлические материалы с ультрамелкозернистой (УМЗ) структурой, полученной путем интенсивной пластической деформации (ИПД), обладают высокой твердостью, прочностными характеристиками при статическом и циклическом нагружениях [1]. Поэтому данные материалы считают перспективными для изготовления конструкций и деталей машин, работающих в экстремальных условиях, в том числе, в условиях нефтегазового комплекса. Однако понятие конструктивной прочности материалов включает в себя, помимо твердости и прочности, ряд других характеристик, не последнее место в котором занимает коррозионная стойкость

Согласно современным теоретическим представлениям [2,3], коррозия наноструктурированных материалов должна ускоряться в активных средах. Однако результаты исследований коррозионных свойств ряда металлических УМЗ материалов, свидетельствуют о более сложной зависимости. Так, например, Oguzie показал [4,5], что после интенсивной прокатки наножелезо больше подвержено коррозии в растворе 0.1 и 0.5 моль/л $\mathrm{H}_{2} \mathrm{SO}_{4}$. О более высокой скорости коррозии УМЗ материалов свидетельствуют и данные работ [6-10]. Другие исследователи [11-13] приводят противоположные результаты. Так, Wang $[11,12]$ показал, что сопротивление коррозии УМЗ железа, полученного интенсивной прокаткой, повышается в растворе $1.0 \mathrm{M}$ /л $\mathrm{HCl}$ и $0.05 \mathrm{M}$ /л $\mathrm{H}_{2} \mathrm{SO}_{4}+0.25 \mathrm{M} /$ л $\mathrm{Na}_{2} \mathrm{SO}_{4}$, по сравнению с крупнозернистым (К3) железом. Song [14] с соавторами на примере Al с УМЗ структурой, а также Vinogradov [15], Rofagha [16], Balyanov [17] с соавторами на примере $\mathrm{Cu}, \mathrm{Ni}$, Ti с УМЗ структурой показали, что основные электрохимические характеристики не изменяются значительно по сравнению с КЗ состоянием. Кроме размера зерна, на коррозионную стойкость наноструктурированных материалов также могут повлиять распределение зерен по размеру [18], текстура [19-20], остаточные напряжения [20] и ряд других факторов.

Целью настоящей работы является установление закономерностей влияния наноструктрирования на скорость коррозии и особенности коррозионных повреждений сталей в сероводородсодержащей среде.

\section{2. Материалы и методики исследования}

В качестве материалов в данной статье использованы низколегированная трубная сталь 9MnSi5 (0.09\% C; $1.26 \% \mathrm{Mn} ; 0.64 \% \mathrm{Si})$ и углеродистые стали: $\mathrm{C} 10(0.11 \% \mathrm{C})$ и $\mathrm{C} 45(0.45 \% \mathrm{C})$. Все стали исследовали в исходном К3 состоянии (после нормализации) и в УМЗ состоянии. Для получения УМЗ состояния стали 9MnSi5, ее подвергали РКУП-конформ [1] по следующий технологии: гомогенизирующий отжиг при температуре $820^{\circ} \mathrm{C}$ с последующей закалкой в воде + отпуск при $350^{\circ} \mathrm{C}+$ РКУП-конформ при $20^{\circ} \mathrm{C}$ (маршрут Вс, $n=4)+$ дополнительный отжиг при $350^{\circ} \mathrm{C}$ с выдержкой
10 мин. С10 исследовали в исходном К3 состоянии (после нормализации) и в УМЗ состоянии, полученном путем РКУП при температуре $200^{\circ} \mathrm{C}$ (маршрут Вс, $n=4$, $\left.\varphi=120^{\circ}\right)$. С45 с К3 структурой исследовали в исходном состоянии (после нормализации), после закалки и среднего отпуска $\left(350^{\circ} \mathrm{C}\right)$, после закалки и высокого отпуска $\left(550^{\circ} \mathrm{C}\right)$. УМЗ состояние было получено путем РКУП по режиму: аустенизация в течение 1 часа при температуре $800^{\circ} \mathrm{C}+$ закалка в воде + средний отпуск $\left(350^{\circ} \mathrm{C}\right)+$ РКУП при $350^{\circ} \mathrm{C}$ (маршрут Вс, $\left.n=6, \varphi=120^{\circ}\right)$.

Тонкую структуру УМЗ сталей исследовали с помощью просвечивающего электронного микроскопа (ПЭМ) JEOL JEM2100. Испытания материалов на твердость проводили на твердомере ТН300. Статическое растяжение цилиндрических образцов с диаметром рабочей части 5 мм из сталей С10 и С45 и образцов из стали $9 \mathrm{MnSi} 5$ с размером рабочей части $4 \times 15$ мм (по 3-4 образца на каждое состояние) проводили на универсальной испытательной машине Н50КТ.

Определение скорости коррозии образцов проводили согласно ГОСТ 9.908-85. В качестве коррозионной среды применяли водный раствор NACE: $5 \% \mathrm{NaCl}+0.5 \% \mathrm{CH}_{3} \mathrm{COOH}$, насыщенный $\mathrm{H}_{2} \mathrm{~S}$, $\mathrm{pH} \leq 3.5$, температура раствора была равна $T=(24 \pm 3)^{\circ} \mathrm{C}$. Сероводород получали из сернистого натрия и соляной кислоты (1:1) на специальной установке. Для приготовления коррозионной среды использовали дистиллированную воду по ГОСТ 6709-72 с рН = 5.4 - 6.6; хлористый натрий по ГОСТ 4233-77 и ледяную уксусную кислоту по ГОСТ 61-75 марки ХЧ; газообразный азот не ниже 1 сорта и сероводород, содержащий примесей не более $0.5 \%$. Время выдержки образцов в растворе составляло 96 часов. Перед испытаниями, а также после испытаний и удаления продуктов коррозии с поверхности образцы взвешивали на аналитических весах с точностью до 4-го знака и определяли скорость коррозии $V_{c}$, кг $/ \mathrm{M}^{2} \cdot c$, по формуле $V_{c}=\left(m_{1}-m_{2}\right) / S \cdot t$, где $m_{1}-$ масса до испытаний, кг; $m_{2}-$ масса после испытаний, кг; $S-$ площадь поверхности образца, $\mathbf{м}^{2}$; $t$ - время выдержки в растворе, с.

Исследование поверхности образцов после коррозионного воздействия проводили с помощью конфокального лазерного сканирующего микроскопа (КЛСM) Lext OLS4000.

\section{3. Результаты исследования и их обсуждения}

Анализ структуры стали 9MnSi5 показал, что после РКУП-конформ имеет место измельчение зерен в среднем до 450 нм (Рис. 1а) с образованием высокой плотности дислокаций. С10 после РКУП имеет средний размер зерна $d_{\mathrm{av}}=300$ нм; структура имеет ярко выраженную полосчатость (Рис. 1b). Средний размер зерен С45 после РКУП составил 560 нм. Зерна относительно равноосные (Рис. 1с). В процессе РКУП наблюдается появление сферического цементита; средний размер образовавшихся карбидов - 27 нм.

Из Табл. 1 видно, что наноструктурирование сталей путем РКУП по вышеуказанным режимам повышает твердость в 1.7-2.3 раза, прочностные 


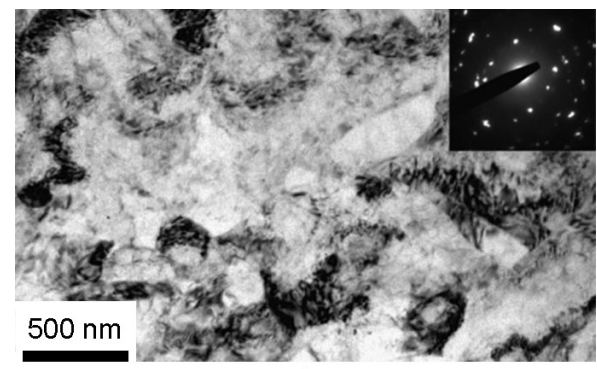

a

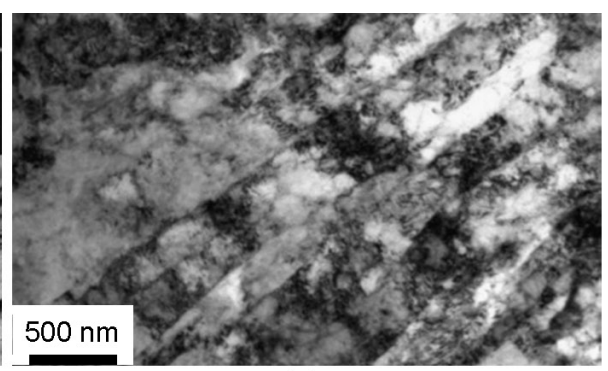

b

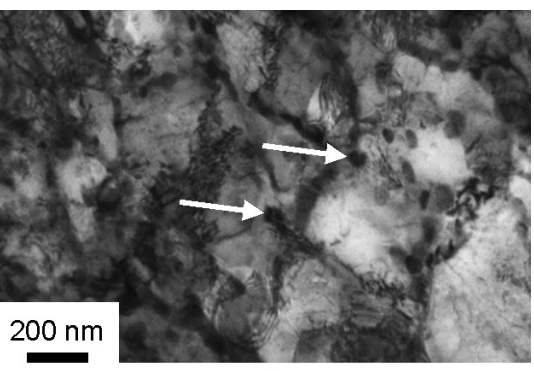

$\mathrm{c}$

Рис. 1. Тонкая структура стали $9 \mathrm{MnSi5}$ (a), C10 (b) и С45 (c) после РКУП (ПЭМ). Стрелками отмечены карбиды.

Fig. 1. Fine structure of steel $9 \mathrm{MnSi5}$ (a), C10 (b) and C45 (c) obtained by ECAP (TEM). Carbides are marked with arrows.

свойства - в 1.7-3.1 раза по сравнению с исходным состоянием. При этом пластичность сталей снижается из-за значительного увеличения дефектов кристаллического строения в УМЗ сталях.

Результаты коррозионных испытаний показали, что все упрочняющие способы обработки сталей увеличивают скорость коррозии (Табл. 1). Однако, как следует из Табл. S1 (дополнительный материал), влияние упрочняющих способов обработки на относительное значение скорости коррозии (по отношению к прочностным характеристикам сталей) не однозначно.

Из Рис. 2а следует, что с повышением твердости сталей, независимо от способа упрочнения, скорость коррозии возрастает. При одинаковом значении твердости сталей с КЗ и УМЗ структурой, последние могут иметь меньшую или большую скорость коррозии по сравнению с КЗ сталями в зависимости от количества углерода и термической обработки КЗ сталей. Кроме того, из Рис. $2 \mathrm{~b}$ следует, что с повышением приращения твердости сталей, приращение скорости коррозии $\left(V_{c} / V_{c \text { init. }}\right)$ имеет тенденцию к снижению. Иными словами, одно и то же приращение скорости коррозии в КЗ сталях достигается при меньших значения приращения твердости по сравнению с УМЗ сталями.

Из Рис. 3 a, b видно, что при одном и том же значении предела прочности и относительного удлинения скорость коррозии УМЗ сталей получен может быть ниже или равна скорости коррозии сталей с КЗ структурой. Иными словами, при одинаковом значении прочности или пластичности сталей с КЗ и УМЗ структурой, стали с УМЗ структурой обладают такой же или большей коррозионной стойкостью по сравнению со сталями с КЗ структурой.

Рассмотрим особенности коррозионного повреждения исследуемых сталей в различном состоянии. Из Рис. $4 \mathrm{a}-\mathrm{c}$, видно, что при воздействии коррозионной среды на КЗ стали в исходном состоянии, помимо общей коррозии в сталях С10 и С45, можно наблюдать коррозионные язвы (Рис. $4 \mathrm{~b}, \mathrm{c}$ ). По-видимому, появление коррозионных язв в КЗ сталях связано с содержанием углерода, а, следовательно, и карбидных фаз. Именно в дефектной структуре стали на границах фаз «феррит-цементит» предпочтительно образование коррозионных язв. Чередующиеся пластины цементита и феррита при электрохимической коррозии (в том

Табл. 1. Количество углерода, средний размер зерна, механические свойства и средняя скорость коррозии сталей в различном состоянии.

Table 1. The amount of carbon, the average grain size, mechanical properties and the average corrosion rate of steels in different states.

\begin{tabular}{|c|c|c|c|c|c|c|c|c|}
\hline $\begin{array}{l}\text { Сталь } \\
\text { Steel }\end{array}$ & C, $\%$ & $\begin{array}{l}\text { Состояние стали } \\
\text { Steel state }\end{array}$ & $\begin{array}{c}d_{\text {cp. }}, \text { мкм } \\
d_{\text {av. }}, \mu \mathrm{m}\end{array}$ & $H B$ & $\begin{array}{l}\sigma_{\mathrm{B}}, \mathrm{M \Pi а} \\
\sigma_{\mathrm{TS}}, \mathrm{MPa}\end{array}$ & $\begin{array}{l}\sigma_{0.2}, \mathrm{M \Pi a} \\
\sigma_{0.2}, \mathrm{MPa}\end{array}$ & $\begin{array}{l}\delta, \% \\
\delta, \%\end{array}$ & $\begin{array}{l}V_{\kappa}, \mathrm{\kappa} \Gamma / \mathrm{M}^{2} \cdot \mathrm{c} \\
V_{c}, \mathrm{~kg} / \mathrm{m}^{2} \cdot \mathrm{s}\end{array}$ \\
\hline \multirow{2}{*}{ 9MnSi5 } & \multirow{2}{*}{0.09} & $\begin{array}{l}\text { Исходное (К3) } \\
\text { Initial (CG) } \\
\end{array}$ & 20 & 143 & 485 & 354 & 27 & $6.222 \cdot 10^{-8}$ \\
\hline & & $\begin{array}{c}\text { После РКУП-конформ (УМЗ) } \\
\text { After ECAP-conform (UFG) }\end{array}$ & 0.45 & 255 & 788 & 595 & 11 & $1.100 \cdot 10^{-7}$ \\
\hline \multirow{2}{*}{$\mathrm{C} 10$} & \multirow{2}{*}{0.11} & $\begin{array}{c}\text { Исходное (K3) } \\
\text { Initial (CG) }\end{array}$ & 15 & 121 & 460 & 350 & 25 & $8.278 \cdot 10^{-8}$ \\
\hline & & $\begin{array}{l}\text { После РКУП (УМЗ) } \\
\text { After ЕСАР (UFG) }\end{array}$ & 0.3 & 235 & 1028 & 989 & 8 & $9.278 \cdot 10^{-8}$ \\
\hline \multirow{4}{*}{ C45 } & \multirow{4}{*}{0.45} & $\begin{array}{l}\text { Исходное (КЗ) } \\
\text { Initial (CG) }\end{array}$ & 10 & 204 & 470 & 345 & 20 & $1.111 \cdot 10^{-7}$ \\
\hline & & $\begin{array}{c}\text { Закалка + средний отпуск (К3) } \\
\text { Hardening + medium tempering (CG) }\end{array}$ & - & 365 & 886 & 742 & 8 & $1.442 \cdot 10^{-7}$ \\
\hline & & $\begin{array}{c}\text { Закалка + высокий отпуск (К3) } \\
\text { Hardening + high tempering (CG) }\end{array}$ & - & 280 & 985 & 839 & 10 & $2.125 \cdot 10^{-7}$ \\
\hline & & $\begin{array}{c}\text { После РКУП (УМЗ) } \\
\text { After ЕСАР (UFG) }\end{array}$ & 0.56 & 341 & 1171 & 1064 & 5 & $2.181 \cdot 10^{-7}$ \\
\hline
\end{tabular}




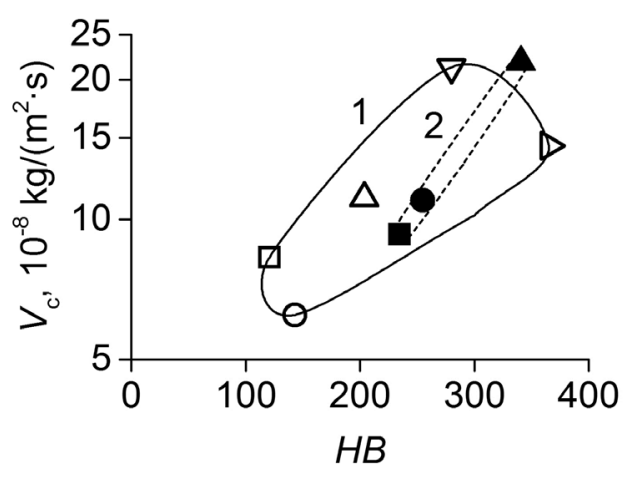

O $9 \mathrm{MnSi5}$, initial

口 C10, initial

$\triangle \mathrm{C} 45$, initial

$\triangleright$ C45, hardening + medium tempering

$\nabla$ C45, hardening +

high tempering

- $9 \mathrm{MnSi5}, \mathrm{ECAP}$

- C10, ECAP

$\triangle$ C45, ECAP

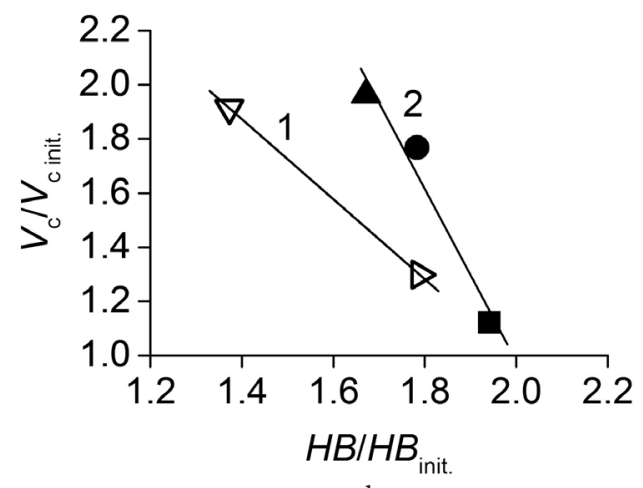

a

b

Рис. 2. Связь скорости коррозии с твердостью сталей (а) и зависимость приращения скорости коррозии от приращения твердости сталей (b). Светлые точки - КЗ стали; темные точки - УМЗ стали.

Fig. 2. The relationship of the corrosion rate with the hardness of the steels (a) and the dependence of the corrosion rate increment on the increment of the hardness of steels (b). Light points - CG steels; dark points - UFG steels.

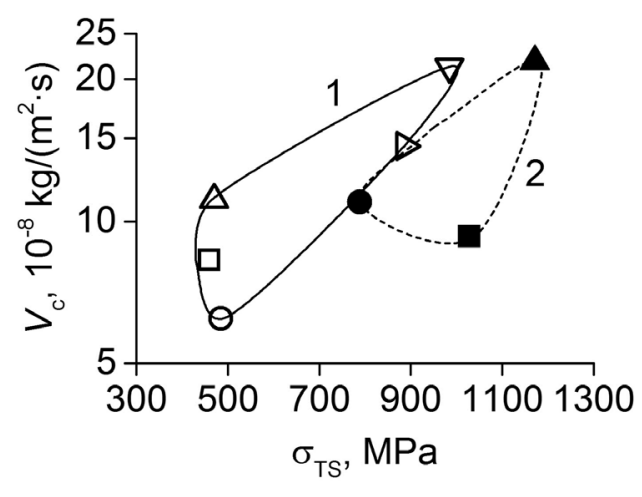

a

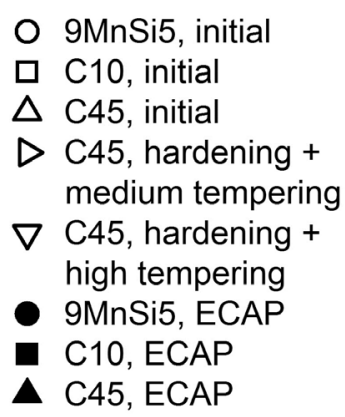

$\triangle$ C45, ECAP

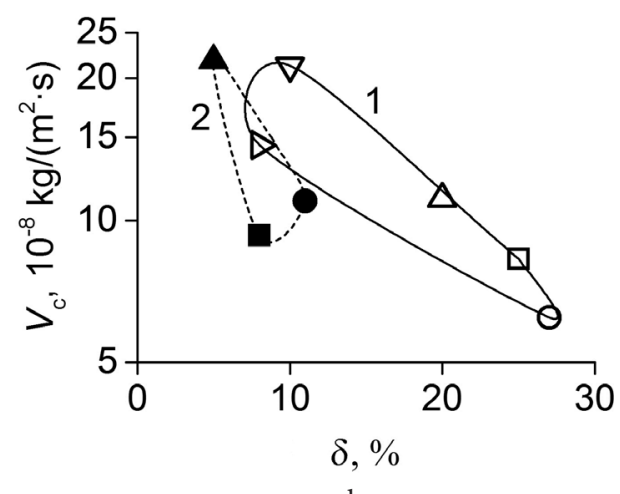

$\mathrm{b}$

Рис. 3. Связь скорости коррозии с пределом прочности (а) и относительным удлинением (b) КЗ сталей (светлые точки) и УМЗ сталей (темные точки).

Fig. 3. Relationship of the corrosion rate with the tensile strength (a) and percentage elongation after fracture (b) of the CG steels (light points) and UFG steels (dark points).

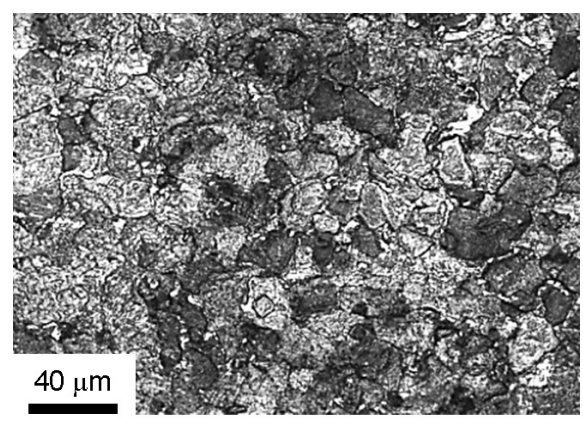

a

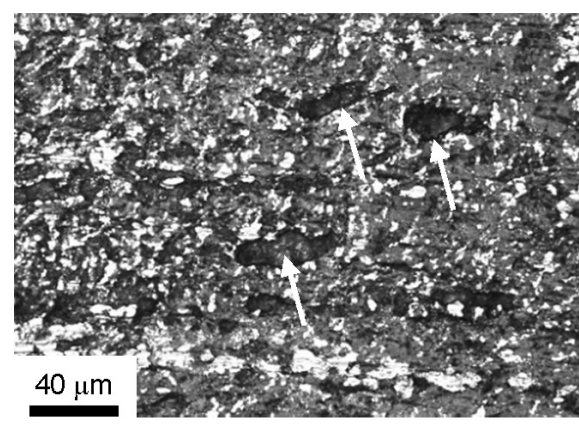

$\mathrm{d}$

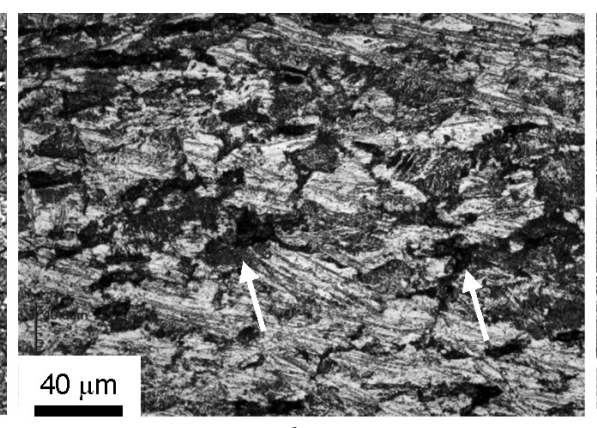

b

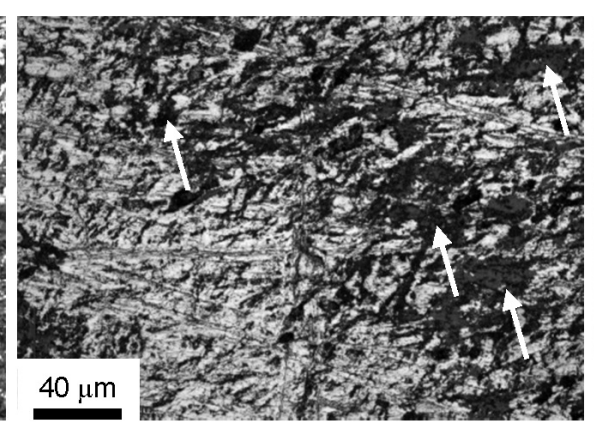

e

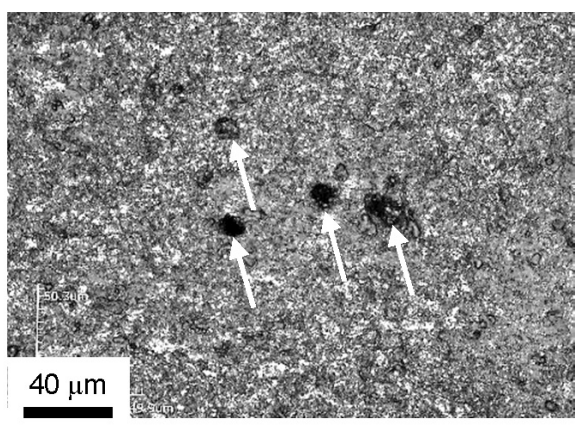

c

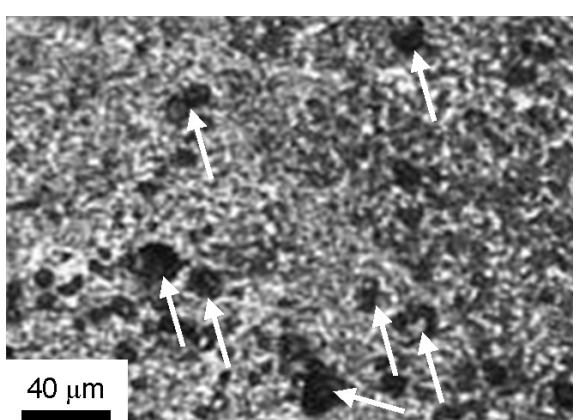

$\mathrm{f}$

Pис. 4. Микрорельеф поверхности образцов из стали $9 \mathrm{MnSi5}(\mathrm{a}, \mathrm{d}), \mathrm{C} 10$ (b, e), C45 (c, f) в исходном состоянии + коррозия (a-c); после РКУП + коррозия (d-f) (КЛСМ). Стрелками указаны некоторые коррозионные язвы. ×1000.

Fig. 4. Microrelief of the surface of samples made from steel $9 \mathrm{MnSi5}(\mathrm{a}, \mathrm{d}), \mathrm{C} 10$ (b, e), C45 (c, f) in the initial state + corrosion (a-c), after ECAP + corrosion (d-f) (CLSM). Arrows indicate some corrosive ulcers. $\times 1000$. 
числе сероводородной) образуют гальванические пары, что провоцирует ускоренное анодное растворение феррита вблизи карбидов. При этом сероводород служит катализатором анодного растворения, хотя детали механизма данного воздействия недостаточно изучены и обсуждаются в литературе. Обычно предполагают, что сероводород, находясь в электролите, приводит к образованию на поверхности стали пленки сульфида железа, которая отслаивается или растворяется, унося атомы железа с поверхности в раствор [21]. Кроме того, некоторые исследователи пришли к выводу, что сульфид $\mathrm{FeS}$, осаждаясь на поверхности стали, служит катодом и провоцирует анодное растворение окружающего металла [22].

После РКУПи коррозионного воздействия в исследуемых сталях доминируют общая коррозия + коррозия пятнами + язвенная коррозия (Рис. $4 \mathrm{~d}-\mathrm{f}$ ). На поверхности образцов из стали $9 \mathrm{MnSi5}$ коррозионные язвы имеют неправильную форму (Рис. $4 \mathrm{~d}$ ) и глубину не более 10 мкм. В образцах из С10 большая часть коррозионных язв имеет правильную округлую форму диаметром 6-9 мкм (Рис. 4е). На поверхности образцов из С45 после РКУП и последующей коррозии на фоне общей коррозии видна коррозия пятнами и большое количество равномерно расположенных округлых коррозионных язв (Рис. 4f) диаметром примерно 10 мкм.

Полученные результаты свидетельствуют о том, что УМЗ стали имеют повышенную склонность к язвенной коррозии по сравнению с КЗ сталями. Наиболее вероятно, ускоренное локальное растворение металла происходит вдоль дислокационных субзеренных и высокоугловых межзеренных границ, плотность которых в сталях с УМЗ структурой существенно выше, чем в сталях с КЗ структурой. Кроме того, можно предположить, что на механизм коррозионного повреждения УМЗ сталей, полученных после РКУП, помимо дефектности структуры и межфазовых границ, существенное влияние, по-видимому, может оказывать пористость материала, неизбежно возникающая при любых видах ИПД. Микрои нанопоры на поверхности образцов могут служить очагами развития коррозионных язв. По этой причине стали с УМЗ структурой в среднем показывают более высокие абсолютные значения скорости коррозии, чем стали с КЗ структурой. Тем не менее, приведенные выше объяснения полученных результатов носят предположительный характер и требуют проведения дополнительных экспериментальных исследований, выполнение которых намечено в рамках комплексного изучения коррозионного поведения сталей с КЗ и УМЗ структурой.

\section{4. Выводы}

Рассмотренные способы упрочняющей обработки сталей увеличивают скорость коррозии в сероводородсодержащих средах, но неоднозначно влияют на скорость коррозии по отношению к твердости и прочности сталей.
При одинаковом значении твердости сталей с КЗ и УМЗ структурой, последние могут иметь меньшую или большую скорость коррозии по сравнению с КЗ сталями. Причем, одно и то же приращение скорости коррозии в КЗ сталях достигается при меньших значениях приращения твердости по сравнению с УМЗ сталями.

При одинаковом значении прочности или пластичности сталей с КЗ и УМЗ структурой, стали с УМЗ структурой обладают такой же или большей коррозионной стойкостью по сравнению с КЗ сталями.

В КЗ сталях доминируют общая и межзеренная коррозия. В УМЗ сталях, полученных путем РКУП, помимо общей коррозии, имеет место коррозия пятнами и язвенная коррозия. С увеличением количества углерода в сталях как с КЗ, так и с УМЗ структурой, количество коррозионных язв увеличивается.

Дополнительный материал/Supplementary Material. Электронная версия статьи содержит дополнительный материал, доступный безвозмездно на сайте журнала (lettersonmaterials.com)./The online version of this paper contains supplementary material available free of charge at the journal's Web site (lettersonmaterials.com).

Благодарности/Aknowledgements. Работа выполнена прифинансовой поддержкеРФФИ(проект 18-08-00340_а). Авторы благодарят профессора В.М. Кушнаренко и научного сотрудника А.В. Ганеева за помощь в проведении экспериментальной части работы./This work was supported by the Russian Fond Fundamental Investigation (RFFI) [grant number 18-08-00340_a]. The authors thank the Professor V.M. Kushnarenko and Researcher A. V. Ganeev for the help in carrying out the experimental part of the work.

\section{Литература/References}

1. R.Z. Valiev, A.P. Zhilyaev, T.G. Langdon. Bulk Nanostructured Materials: Fundamentals and Applications. Hoboken, New Jersey, John Wiley \& Sons (2014) 440 p. Crossref

2. R. Song, D. Ponge, D. Raabe, J. G. Speer, D. K. Matlock. Materials Science and Engineering A. 441, 1 (2006). Crossref

3. K.D. Ralston, N. Birbils, C.H. J. Davies. Scr. Mater. 63, 1201 (2010). Crossref

4. E. E. Oguzie, S. G. Wang, Y. Li, F. H. Wang. J. Solid State Electrochem. 12, 721 (2008). Crossref

5. E. E. Oguzie, S. G. Wang, Y. Li, F. H. Wang. J. Phys. Chem. C. 113,8420 (2009). Crossref

6. G.V. Klevtsov, R.Z. Valiev, V.M. Kushnarenko, N. A. Klevtsova, E.D. Merson, I.N. Pigaleva. Russian Journal of Non-Ferrous Metals. 58 (2), 142 (2017). Crossref

7. R.Z. Valiev, G.V. Klevtsov, N.A. Klevtsova, V. M. Kushnarenko, A. V. Ganeev. Steel in Translation. 44, 6, 418 (2014). Crossref

8. G. V. Klevtsov, R.Z. Valiev, V.M. Kushnarenko, N. A. Klevtsova, E. D. Merson, I. N. Pigaleva, A. V. Ganeev. Korroziya: Materialy, Zashchita. 11, 22 (2016). (in 
Russian) [Г. В. Клевцов, Р. З. Валиев, В. М. Кушнаренко, Н.А. Клевцова, Е.Д. Мерсон, И.Н. Пигалева, А. В. Ганеев. Коррозия: материалы, защита. 11, 22 (2016).]

9. G. V. Klevtsov, R.Z. Valiev, V.M. Kushnarenko, N.A. Klevtsova, E.D. Merson, A.V. Ganeev, I.N. Pigaleva. Korroziya: Materialy, Zashchita. 10, 13 (2016). (in Russian) [Г.В. Клевцов, Р.3. Валиев, В.М. Кушнаренко, Н.А. Клевцова, Е.Д. Мерсон, А. В. Ганеев, И.Н. Пигалева. Коррозия: материалы, защита. 10, 13 (2016).]

10. G.V. Klevtsov, R.Z. Valiev, V.M. Kushnarenko, N. A. Klevtsova, E. D. Merson, I. N. Pigaleva, A. V. Ganeev. Korroziya: Materialy, Zashchita. 7, 14 (2017). (in Russian) [Г.В. Клевцов, Р.З. Валиев, В.М. Кушнаренко, Н.А. Клевцова, Е.Д. Мерсон, И.Н. Пигалева, А.В. Ганеев. Коррозия: материалы, защита. 7, 14 (2017).]

11. S. G. Wang, C. B. Shen, K. Long, H.Y. Yang, F. H. Wang, Z. D. Zhang. J. Phys. Chem. B. 109, 2499 (2005). Crossref

12. S. G. Wang, C.B. Shen, K. Long, T. Zhang, F.H. Wang, Z.D. Zhang. J. Phys. Chem. B. 110, 377 (2006). Crossref
13. Z. J. Zheng, Y. Gao, Y. Gui, M.Zhu. Corros. Sci. 54, 60 (2012). Crossref

14. D. Song, A. Ma, J. Jiang, P. Lin, D. Yang. Trans. Nonferrous Met. Soc. China. 19, 1065 (2009). Crossref

15. A. Vinogradov, T. Mimaki, S. Hashimoto, R. Valiev. Scripta Mater. 41, 319 (1999). Crossref

16. A. Rofagha, R. Langer, A.M. El-Sherik, U. Erb, G. Palumbo, K.T. Aust. Scripta Met. Mater. 25, 2867 (1991). Crossref

17. A. Balyanov, J. Kutnyakova, N.A. Amirkhanova, V.V. Stolyarov, R.Z. Valiev, X.Z. Liao, Y.H. Zhao, Y.B. Jiang, H.F. Xu, T. C. Lowe, Y.T. Zhu. Scripta Mater. 51, 225 (2004). Crossref

18. S. Gollapudi. Corros. Sci. 62, 90 (2012). Crossref

19. Z. Pu, G. L. Song, S. Yang, J. C. Outeiro, Jr. O. W. Dillon, D. A. Puleo, I.S. Jawahir. Corros. Sci. 57, 192 (2012). Crossref

20. N. N. Aung, W. Zhou. Corros. Sci. 52, 589 (2010). Crossref

21. X. Wen, P. Bai, B. Luo, S. Zheng, C. Chen. Corros. Sci. 139, 124 (2018). $\underline{\text { Crossref }}$

22. P.P. Bai, Y.X. Liang, S.Q. Zheng, C.F. Chen. Ind. Eng. Chem. Res. 55 (41), 10932 (2016). rossref 